\title{
The occurrence altitudes of middle atmospheric temperature inversions and mesopause over low-latitude Indian sector
}

\author{
M. Sivakandan ${ }^{1}$, D. Kapasi ${ }^{2}$, and A. Taori ${ }^{1}$ \\ ${ }^{1}$ National Atmospheric Research Laboratory, Gadanki - 517 112, India \\ ${ }^{2}$ St. Joseph's College Autonomous, Lalbagh Road, Bangalore - 560 027, India \\ Correspondence to: A. Taori (alok.taori@gmail.com)
}

Received: 19 May 2014 - Accepted: 11 July 2014 - Published: 19 August 2014

\begin{abstract}
We study the occurrence characteristics of mesospheric inversion layers (MILs) in the $60-105 \mathrm{~km}$ altitude region over the low-latitude Indian sector. We note that lower inversions in the mesospheric temperatures occur in the 70$75 \mathrm{~km}$ altitude regions while the upper inversions occur in 90-95 km altitude regions. The mesopause altitude is mostly noted to be $\sim 98 \mathrm{~km}$ with the night-time mesopause (particularly in the year 2002) showing a small peak in the mesopause occurrence at $\sim 75 \mathrm{~km}$ altitude. We note higher occurrence rate of MILs during high solar activity year compared to low solar activity year. It is also observed that night time MILs show a systematic seasonal variability, with higher occurrence of single and double temperature inversions during equinoxes.
\end{abstract}

Keywords. Space plasma physics (laboratory studies)

\section{Introduction}

The mean thermal structure of the Earth's middle atmosphere is characterized by a negative temperature gradient. The lack of heating mechanisms and dominance of infrared cooling triggers the occurrence of the coldest region, known as "mesopause". It is also understood that gravity wave, tides and planetary waves govern the middle atmospheric variability. Therefore, these dynamical processes contribute significantly to the variability noted in the mesospheric structures and may influence the mesopause altitude (Hargreaves, 1992). The mesopause is also an altitude in which higher and lower regions have different heat exchange processes, making it vulnerable from both sides.

There are several reports showing positive temperature gradients in the mesosphere which are in contrast to the ideal situation of negative gradients (Meriwether and Gardner, 2000; Gan et al., 2012, and references cited therein). This kind of phenomenon is known as "mesospheric inversion layer (MIL)". It was first observed by Schmidlin (1976) and later defined by Leblanc and Hauchecorne (1997). Since then, several investigators have studied the characteristics of the MILs. For example, States and Gardner (1998) from the North American sector reported the diurnal tides and thermospheric heat-induced inversions. From the South American sector Fechine et al. (2008) reported the occurrence of lower mesospheric inversions using space-borne temperature measurements. From the Indian sector, Sivakumar et al. (2001) and Fadanavis and Beig (2004) reported the lower temperature inversions to occur at 73 to $79 \mathrm{~km}$ altitudes, peaking around $76 \mathrm{~km}$ with 20 to $32 \mathrm{~K}$ amplitudes. Recently, Szewczyk et al. (2013) reported the turbulence-triggered double mesospheric inversions at altitudes of $71-73 \mathrm{~km}$ and $86-89 \mathrm{~km}$ respectively.

In general, ground-based lidars are used to study the characteristics of MILs. Establishing the statistics is difficult by ground-based optical instruments because of their dependency on the availability of clear nights for regular observations. The Thermosphere Ionosphere Mesosphere Energetics and Dynamics (TIMED) satellite mission having a payload named Sounding of the Atmosphere using Broadband Emission Radiometry (SABER) provides an opportunity to fill this gap. Using SABER measurements, Fechine et al. (2008) studied the characteristics of the MILs over the South American sector $\left(17^{\circ} \mathrm{S}-3^{\circ} \mathrm{N}, 26-40^{\circ} \mathrm{W}\right)$ and found a semi-annual oscillation in the occurrence rate. Recently, Gan et al. (2012) studied the occurrence characteristics of low-altitude MILs throughout the globe and found that gravity and planetary waves play an important role in understanding the observed 
amplitudes of the MILs. They also found that the MILs show strong seasonal variations and peaks in spring and autumn and often the lower MIL peak is located at $76 \mathrm{~km}$.

The present study is aimed at extending some of the above space-borne investigation to the Indian latitudes, using the SABER data. In this study, we characterize the altitude occurrences of MILs over the equatorial Indian latitudes.

\section{Instrument}

The SABER is one of the four instruments onboard in TIMED satellite. It scans the horizon, observing limb emission in 10 broadband spectral channels ranging from 1.27 to $17 \mu \mathrm{m}$ (Russell III et al., 1999). It provides vertical temperature profiles, key chemical constituents, and emission features over a broad altitude range during both day and night. The TIMED satellite flies in a nadir-pointing orientation from its $625 \mathrm{~km}$ circular orbit at $74.1^{\circ}$ inclination and period of about $102 \mathrm{~min}$. SABER kinetic temperature is retrieved from two $15 \mu \mathrm{m}$ and one $4.3 \mu \mathrm{m} \mathrm{CO}_{2}$ radiometer channel measurements in the tangent height range spanning approximately $15-120 \mathrm{~km}$. The local and nonlocal thermodynamic retrieval algorithms are used respectively at altitude below $70 \mathrm{~km}$ and in the upper mesosphere. Latitude coverage of SABER limb observations extends from $52^{\circ} \mathrm{N}$ to $83^{\circ} \mathrm{S}$ or from $52^{\circ} \mathrm{S}$ to $83^{\circ} \mathrm{N}$. Below $95 \mathrm{~km}$, the overall error in the retrieved kinetic temperature is around $\sim 1.5 \mathrm{~K}$ at low and mid latitudes with maximum error at $104 \mathrm{~km}$ being $\sim 4-5 \mathrm{~K}$ (Garcia-Comas et al., 2008). In the present work, we used TIMED/SABER kinetic temperature data to study the occurrence of mesospheric inversions and their characteristics over equatorial Indian region ( 0 to $10^{\circ} \mathrm{N}$ and 70 to $90^{\circ} \mathrm{E}$ ) for the year 2002 (solar maximum) and 2008 (solar minimum).

\section{Observation}

A typical time-, latitude- and longitude-averaged SABER temperature profile corresponding to the night (18:00-06:00 Indian Standard Time, IST) is shown in Fig. 1. On this night (12 March 2008) there were three SABER profiles at time 23:30 IST, in the selected spatial grid mentioned above. The MSISE-00 (Batten et al., 1987) temperature profile corresponding to this night for $6^{\circ} \mathrm{N}, 80^{\circ} \mathrm{E}$ at 20:00 IST is shown as solid red lines. We note that the observed temperature shows large deviations from the MSISE expectations. Such differences reveal deviation of thermodynamical state of the mesosphere from the ideal hydrostatic one, caused by the variable forcing such as gravity wave and tides and their interplay with the chemical species (Meriwether and Gardner, 2000). As stated in the Introduction, these are known as the mesospheric temperature inversions or the mesospheric inversion layers (MIL). The identification used in the present study is shown as $L_{i}$ and $M_{i}$, denoting low and maximum altitude of the $i$ th inversion. The altitude difference between

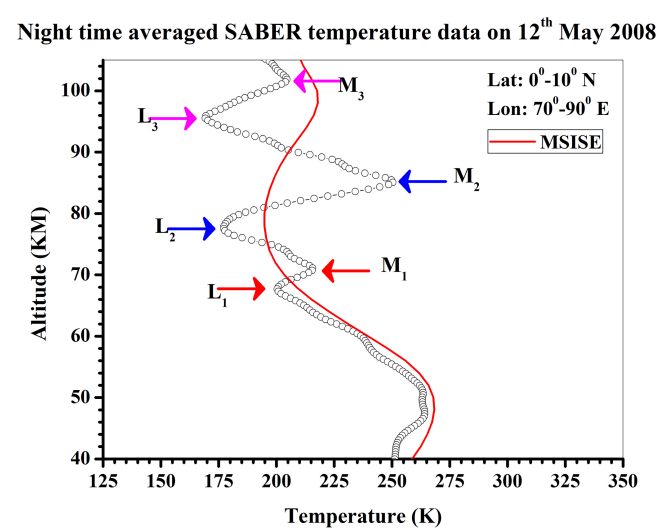

Figure 1. A sample middle atmospheric temperature profile obtained by SABER measurements averaged for a grid corresponding to $0-10^{\circ} \mathrm{N}$ and $70-90^{\circ} \mathrm{E}$. The measurements are shown as open circles while the MSISE00 model estimates are plotted as a red line. The $L_{i}$ and $M_{i}$ correspond to the altitudes of lower and maximum temperature for the evident $i$ th structure in the data. Note the occurrence of minimum temperature at $L_{3}$ which is taken as the mesopause altitude.

$L_{i}$ and $M_{i}$ is termed as the thickness, while the modulus of temperature difference between $L_{i}$ and $M_{i}$ is termed as the amplitude of the $i$ th MIL (Meriwether and Gardner, 2000). It is important to state that the mesopause altitude may be any one of the $L$ values. We identify the mesopause altitude by the minimum temperature value. On this day, mesopause altitude is situated at about $96 \mathrm{~km}$ with the coldest temperature being $168 \mathrm{~K}$. We do not consider the temperature inversions above $104 \mathrm{~km}$ because the errors increase non-linearly (Garcia-Comas et al., 2008) beyond this. Because the total maximum error in the temperature estimate is $\sim 4-5 \mathrm{~K}$ at $104 \mathrm{~km}$, whenever temperature difference between $L_{i}$ and $M_{i}$ is $<5 \mathrm{~K}$, we have considered the MIL to be insignificant. However, on this night, we can conclude that there are 2 MILs occurring at $\sim 69$ and $\sim 78 \mathrm{~km}$ with mesopause occurring at $\sim 96 \mathrm{~km}$.

We carried out similar analysis for mean temperature profiles obtained for daytime (06:00-18:00 IST) and night-time (18:00-06:00 IST), separately, for each day number during year 2002 and 2008 representing the high and low solar activity, respectively. Apart from the characterizing the altitude distribution of MILs, we show that it is not necessary that $L_{3}$ is always a mesopause altitude. The seasonal variability of MILs and mesopause is also discussed during high and low solar activity period. In year 2002, total numbers of mean daytime profiles are 173 while the numbers of mean night-time profiles are 271. Similarly in year 2008, numbers of mean daytime and night-time profiles are 183 and 298 respectively. These numbers indicate that the data statistics used in both years are comparable. 

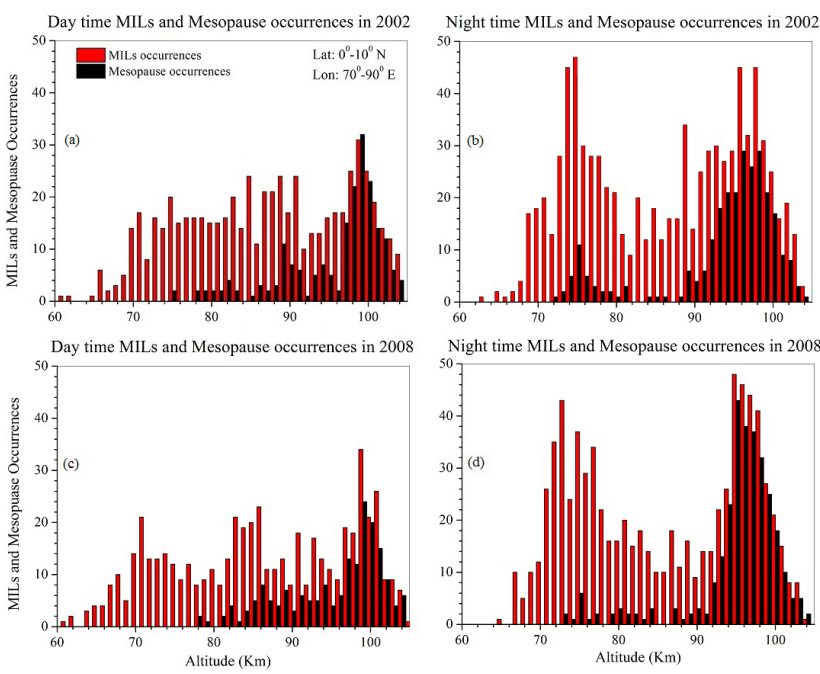

Figure 2. The altitude distribution of the MIL occurrences and the mesopause occurrences for the year 2002 during daytime (a) and night-time (b) and year 2008 during daytime (c) and night-time (d). The red bars show the MIL occurrences while the black bars represent the mesopause altitudes. One may note that upper inversions do not always represent the mesopause altitudes.

\section{Results}

The altitudes of MIL occurrences against the frequency (number of times the MILs occurred) are plotted in Fig. 2. The top panel shows the MIL altitude-frequency plot for year 2002 with the left panel displaying the daytime statistics (Fig. 2a) while the right panel depicts the night-time statistics (Fig. 2b). The red bars show the occurrences of the MILs while the black bars show the mesopause altitudes. We note that during daytime, the MILs occur uniformly in 70-95 km altitude regions and most of the times MILs occurring above $96 \mathrm{~km}$ are nothing but a signature of the mesopause altitude. However, there are $5 \%$ cases in the daytime when this is not true. In the case of mesopause occurrences, we note that during daytime, mesopause is mostly situated at the $97-100 \mathrm{~km}$ altitude region. The night-time MIL altitude-frequency plot reveals clear distinction of the preferred altitudes of MIL occurrence. We find that MILs tend to occur either near to $75 \mathrm{~km}$ altitudes or $96 \mathrm{~km}$ altitudes. There are a significant number of instances when MILs occur in 80-90 km altitudes - however, distribution suggests them to be at the wings of a Gaussian distribution. We note that mesopause occurrence also shows a double peak with a small one situated around $75 \mathrm{~km}$ and the bigger peak at $96-98 \mathrm{~km}$ altitudes. We also note that there are about $10 \%$ instances when MILs occur above $90 \mathrm{~km}$ and do not fall in the category of mesopause.

The MIL altitude-frequency plots for the year 2008 are shown in the bottom panels of Fig. 2. The daytime distribution is shown in Fig. 2c while the night-time occurrences are shown in Fig. 2d. Similar to the case of year 2002, during

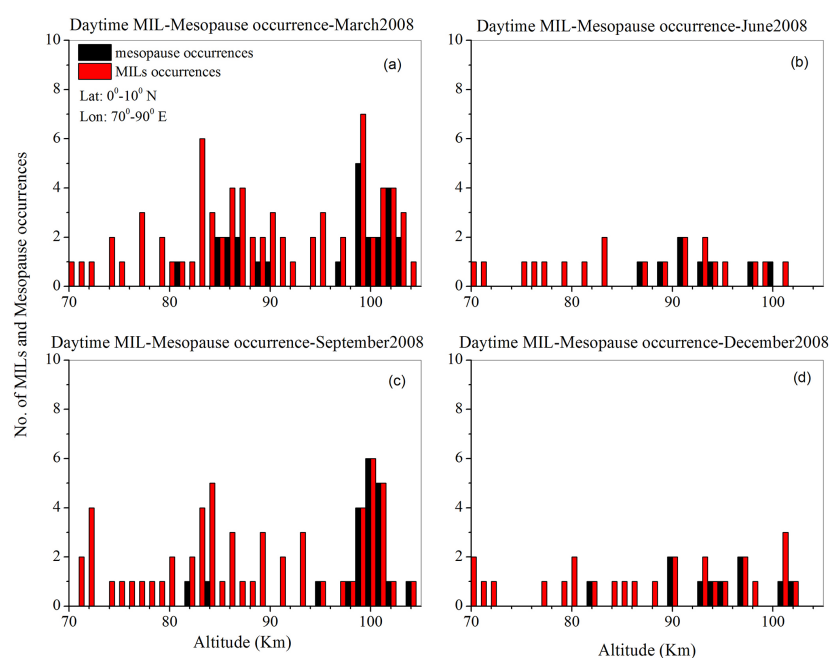

Figure 3. Altitude distribution of MILs and mesopause occurrences during March, June, September and December months for the daytime measurements of year 2008 revealing the seasonal behaviour.

daytime, the MILs seems to have no strong preferences as far as the altitude is concerned. The mesopause altitudes seem to peak around $95-98 \mathrm{~km}$. We expected the MILs occurring above $90 \mathrm{~km}$ to represent the mesopause altitude, however about $12 \%$ times, the mesopause occurred somewhat below, and the MILs were recorded at higher altitudes. The nighttime MIL occurrences show clear double peak distribution. The lower MILs peak occur around $72 \mathrm{~km}$ altitude, while the higher MILs peak is noted to be around $95 \mathrm{~km}$. Also, the coldest temperatures (i.e. the mesopause) seem to occur around $95 \mathrm{~km}$ with very small number of occurrences at lower altitudes.

To address the possible seasonal variation of the distribution, we study the above discussed MILs altitude-frequency relation during the equinoxes (March and September), summer and winter (June and December) months. Figure 3 plots the MIL altitude-frequency distribution for the daytime profiles of March (Fig. 3a), June (Fig. 3b), September (Fig. 3c) and December (Fig. 3d) 2008. We note that in both years, 2002 (not shown) and 2008, the MIL occurrence rates are highest in the March and September months (i.e. the equinoxes) which agrees well with earlier reported results (Fadanavis and Beig, 2004; Fechine et al., 2008; Gan et al., 2012). Also plotted is the mesopause altitude (black bars) which clearly suggests that in March there are two distinct levels of mesopause, which are observed around $85-87 \mathrm{~km}$ and $99-102 \mathrm{~km}$ altitudes respectively. However, most of the times, the mesopause altitude is found to be $\sim 99 \mathrm{~km}$. In September months the upper inversion is in fact the mesopause altitude. The night-time plot of the MIL altitude-frequency distribution is shown in Fig. 4. Two peak altitudes of MIL occurrence are noticeable in March and September months (Fig. 4a, c). However, contrary to the 

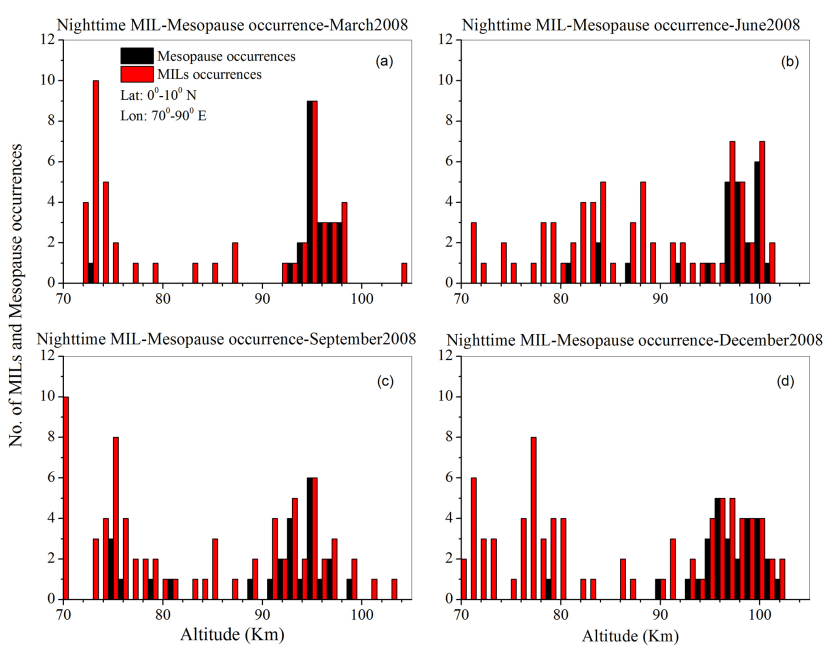

Figure 4. As Fig. 3, but for the night-time measurements.

daytime profiles, June month shows a large occurrence of MILs (Fig. 4b). It is noteworthy that there is no specific altitude preference in June, in contrast to the other months. Similarly, December also reveals large occurrence of MILs. In short, the seasonal behaviour of MIL occurrences is not very clear in the night-time, while daytime profiles clearly show the maximum occurrences of MILs during equinoxes.

As stated earlier, there are occasions when multiple inversions are noted in the data. The statistics of MIL occurrences are shown in Table 1. We noted the maximum of four notable inversions with amplitude $>5 \mathrm{~K}$. The data clearly suggest that most often it is the single or double inversions which occur. The single inversion occurrence rate is $\sim 48 \%$ during the year 2008 while it is only $\sim 32 \%$ in the year 2002; double inversion occurrence rate in the year 2008 is $\sim 39 \%$ while in the year 2002 it is $\sim 35 \%$. The occurrence of three inversions is more in year $2002(\sim 25 \%)$ than in year $2008(\sim 10 \%)$. The seasonal distribution of single, double and triple inversions are shown in Fig. 5. It can be noted that during nighttime (Fig. 5b, d), seasonal variations show a semi-annual nature with peaks of single and double inversions occurring near to the April and October months, while there is a small peak in triple inversions in summer months. Also noteworthy is that there is no specific seasonal preference in the daytime occurrences.

Apart from the altitude of occurrence, the MILs are characterized using thickness and amplitude. As stated earlier, in Fig. 1 the altitude difference between $L_{i}$ and $M_{i}$ is termed as the thickness, while the modulus of temperature difference between $L_{i}$ and $M_{i}$ is termed as the amplitude of the $i$ th MIL. We estimated the monthly mean thickness and amplitudes of MILs which are shown in Fig. 6a (for year 2002) and Fig. $6 \mathrm{~b}$ (for year 2008). The error bars show the standard deviations in the monthly averaged data. It is noteworthy that thickness as well as the amplitudes show peaks near to the equinoxes. These peaks are more pronounced
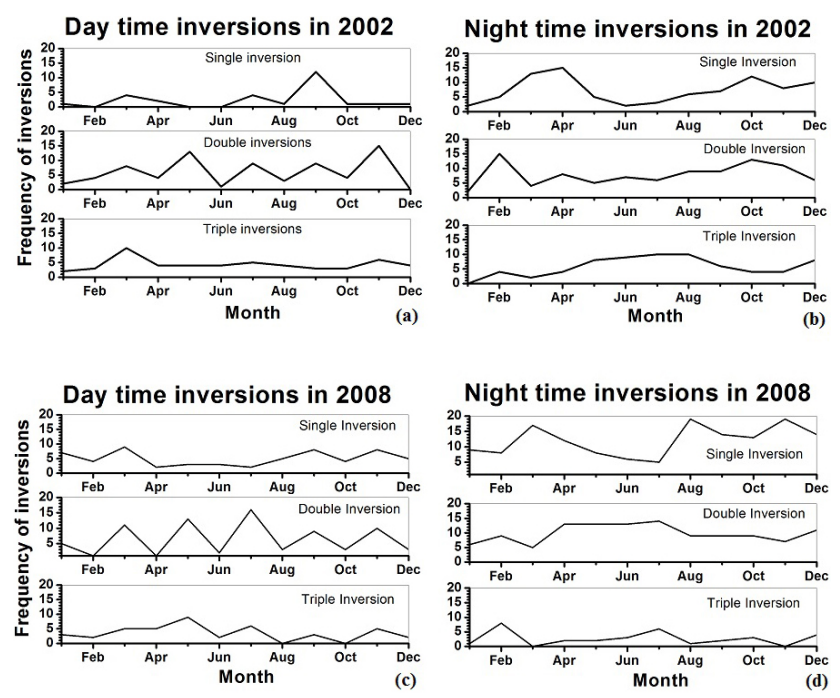

Figure 5. Occurrence characteristics of single, double and triple inversions, during daytime (a, c) and night-time $(\mathbf{b}, \mathbf{d})$ of the year 2002/2008.

in the night-time data (shown in bottom panels of Fig. 6a and b) instead of daytime. It is evident that there is no significant difference between the characteristics noted in the years 2002 and 2008. The variations of mesopause altitude and temperature (i.e. the minimum of temperature altitudes) are shown in Fig. 6c (for year 2002) and Fig. 6d (for year 2008). The error bars represent the standard deviations in the monthly average values. We note that in year 2002, during daytime, monthly mean mesopause height varies from $\sim 92$ to $\sim 98 \mathrm{~km}$ while the mesopause temperature varies from $\sim 160$ to $\sim 178 \mathrm{~K}$. This variability range is noted to be nearly the same in night-time data as well, with evident seasonal variability. The year 2008 data reveal the mesopause altitude to vary from $\sim 90$ to $\sim 98 \mathrm{~km}$ which is somewhat similar to that noted in year 2002. However, the temperature values in year 2008 vary from $\sim 152$ to $\sim 168 \mathrm{~K}$ during daytime, and $\sim 152$ to $\sim 162 \mathrm{~K}$ during night-time which is a temperature range significantly less than the one noted in year 2002.

In order to investigate whether there was a systematic difference between the observed mesopause temperatures in high solar activity year 2002 and low solar activity year 2008, representing each day and night as stated earlier in the temperature steps of $1 \mathrm{~K}$, we plotted the frequency distribution of mesopause temperatures as shown in Fig. 7. In each plot, we best-fitted a Gaussian curve (blue lines) on this distribution to characterize the mesopause temperatures (red bars). For year 2002 (Fig. 7a, b), we find that the distribution has a mean value $163.3 \mathrm{~K}$ with standard deviation of $25.8 \mathrm{~K}$ during daytime and $167.7 \mathrm{~K}$ with $26.2 \mathrm{~K}$ standard deviation during night-time. The mesopause temperature values observed during year 2008 are shown in Fig. 7c, d. We note that the mesopause temperature distribution is characterized by the mean values $161.5 \mathrm{~K}$ with standard deviations $24.2 \mathrm{~K}$ during 
Table 1. Statistics of multiple mesospheric inversion layer (MIL) occurrences during the years 2002 and 2008.

\begin{tabular}{|c|c|c|c|c|c|c|c|c|}
\hline \multirow[b]{3}{*}{ Inversions } & \multicolumn{4}{|c|}{2002} & \multicolumn{4}{|c|}{2008} \\
\hline & \multicolumn{2}{|c|}{ Day } & \multicolumn{2}{|c|}{ Night } & \multicolumn{2}{|c|}{ Day } & \multicolumn{2}{|c|}{ Night } \\
\hline & Nos. & $\%$ & Nos. & $\%$ & Nos. & $\%$ & Nos. & $\%$ \\
\hline Zero & 0 & 0 & 0 & 0 & 1 & & 1 & \\
\hline Single & 27 & 15.6 & 88 & 32.47 & 60 & 32.78 & 144 & 48.32 \\
\hline Double & 72 & 41.6 & 95 & 35.05 & 77 & 42.07 & 118 & 39.59 \\
\hline Triple & 52 & 30.05 & 69 & 25.46 & 42 & 22.95 & 32 & 10.73 \\
\hline Four & 18 & 10.4 & 18 & 6.64 & 2 & 1 & 3 & 1 \\
\hline Five & 4 & 2.31 & 1 & & 1 & & 0 & 0 \\
\hline Total & 173 & 99.96 & 271 & 99.62 & 183 & 98.8 & 298 & 99.64 \\
\hline
\end{tabular}

daytime and $162.6 \mathrm{~K}$ with $32.8 \mathrm{~K}$ standard deviation during night-time. This suggests a colder mesopause in the year 2008 compared to the year 2002.

\section{Discussion}

As stated earlier, the statistics on the data availability is comparable for years 2002 and 2008 in the selected latitudelongitude grid. In 2002, total numbers of MIL occurrences during the daytime and night-time were 614 and 861 respectively. The total numbers of MIL occurrences during the daytime and night-time in 2008 were 540 and 796, respectively. This comparison clearly suggests that during 2002 a greater number of MILs occurred. We can see in Fig. 2 that in year 2002, during daytime, the MILs do not reveal specific altitude preferences, while in night-time they do show two preferred altitudes. During the year 2008, daytime MILs show clear preferences $(71,82-86$ and $98-100 \mathrm{~km})$ with night-time MIL occurrences peaking at 73 and $95 \mathrm{~km}$. Earlier, from the Indian sector, Fadanvis and Beig (2004) reported the bottom altitude of lower MILs to be $\sim 74 \mathrm{~km}$ which agrees well with the present investigation. Similarly, Fechine et al. (2008) suggest the bottom altitude of lower MILs to be around 70$72 \mathrm{~km}$, while in a recent report Gan et al. (2012) suggest the average height of lower MILs to be $\sim 75 \mathrm{~km}$ over $10-15^{\circ} \mathrm{N}$ latitudes. Therefore, our results agree well with the recently reported values. Further, the present report also distributes the occurrences of single, double and triple MILs with respect to the months, where it is noted that single and double inversions clearly show peaks near to the equinoxes. Thus our results agree with earlier reports suggesting peaks near to the equinoxes (e.g. Fadanvis and Beig, 2004; Fechine et al., 2006; Gan et al., 2012).

The new aspect of the present investigation is the distribution of multiple MIL occurrences, which show preferred occurrences at $\sim 72-76, \sim 82-86$ and $\sim 95-99 \mathrm{~km}$ altitudes and distinguishes them from the mesopause altitudes. When it comes to the MIL amplitudes, we note that the daytime MIL peaks are significantly smaller than the observed in the night-time. Further, the night-time MIL amplitudes range from 10 to $60 \mathrm{~K}$ with maximum amplitudes near to the equinox months which is in agreement with earlier reports (e.g. Fechnie et al., 2008; Gan et al., 2012). To further elaborate the importance of multiple inversions noted, we quantify their amplitude and thickness in Table 2. We note that the perturbation amplitudes as well as thickness are largest when only single inversion is noted. Also, maximum amplitudes are noted to occur near to the equinox period (as stated earlier), as far as the single and double inversions are concerned. The multiple inversions are noted to be higher in 2002 than in 2008. The average amplitudes of single inversion in year 2002 in day (night) is noted to be $\sim 39 \mathrm{~K}(\sim 43 \mathrm{~K})$ with thickness being $\sim 7.5 \mathrm{~km}(7.4 \mathrm{~km})$ while, for the year 2008 the amplitude is estimated to be $\sim 36 \mathrm{~K}(\sim 42 \mathrm{~K})$ with thickness of $\sim 6.7 \mathrm{~km}(\sim 7.4 \mathrm{~km})$. We can see from Table 2 that the amplitudes as well as the thickness of inversions are significant. This, together with Table 1, suggests that not only the occurrences of multiple inversions, but also their thermodynamical signatures are important and not well explored as most of the earlier investigations focused either on lower MILs or the upper MILs. It is also true that in the search of the MILs over the low-latitude Indian sector, we have not used zonal averages of the SABER profiles and may have included short-scale features as well. Aspects related to this and differences from the present investigation may provide clues to the contribution of various wave and tidal components in the generation of multiple MILs and are a subject of future study.

The semi-annual occurrence characteristics of MILs are expected to be due to dynamical as well as chemical processes occurring at mesospheric altitudes. There are reports that exothermic chemical reactions can provide temperature rise as high as $40 \mathrm{~K}$ (Meriwether and Mlynczak, 1995). Investigations by Fadanvis and Beig (2004) showed a good correlation between ozone concentration and the occurrences of lower MILs. They suggested chemical heating to play a major role. Gravity wave breaking is also expected to be one of the causes (Leblanc and Hauchecorne, 1997). However, simulation studies suggested this to contribute only $\sim 10-15 \mathrm{~K}$ 
Table 2. The amplitude and thickness of multiple mesospheric inversion layers observed in the years 2002 and 2008 together with their standard deviations depicting the variability.

\begin{tabular}{|c|c|c|c|c|c|c|c|c|}
\hline \multirow[b]{3}{*}{ Inversions } & \multicolumn{4}{|c|}{2002} & \multicolumn{4}{|c|}{2008} \\
\hline & \multicolumn{2}{|c|}{ Day } & \multicolumn{2}{|c|}{ Night } & \multicolumn{2}{|c|}{ Day } & \multicolumn{2}{|c|}{ Night } \\
\hline & $\begin{array}{l}\text { Thickness } \\
(\mathrm{km})\end{array}$ & $\begin{array}{l}\text { Amplitude } \\
(\mathrm{K})\end{array}$ & $\begin{array}{l}\text { Thickness } \\
(\mathrm{km})\end{array}$ & $\begin{array}{l}\text { Amplitude } \\
(\mathrm{K})\end{array}$ & $\begin{array}{c}\text { Thickness } \\
(\mathrm{km})\end{array}$ & $\begin{array}{l}\text { Amplitude } \\
(\mathrm{K})\end{array}$ & $\begin{array}{l}\text { Thickness } \\
(\mathrm{km})\end{array}$ & $\begin{array}{l}\text { Amplitude } \\
(\mathrm{K})\end{array}$ \\
\hline Single & $7.5 \pm 2$ & $39.2 \pm 12$ & $7.4 \pm 2$ & $43.5 \pm 22$ & $6.7 \pm 2$ & $36 \pm 13$ & $7.4 \pm 1$ & $42.2 \pm 15$ \\
\hline Double & $4.9 \pm 0.6$ & $23.8 \pm 6$ & $4.9 \pm 0.9$ & $24.4 \pm 9$ & $4.6 \pm 0.7$ & $22.6 \pm 6$ & $5 \pm 0.5$ & $23.7 \pm 8$ \\
\hline Triple & $3.6 \pm 0.4$ & $19.2 \pm 5$ & $3.9 \pm 0.5$ & $18.1 \pm 5$ & $3.9 \pm 0.3$ & $17 \pm 3$ & $3.8 \pm 0.5$ & $15.1 \pm 4$ \\
\hline Four & $3.5 \pm 0.5$ & $14.3 \pm 2$ & $3.4 \pm 0.3$ & $16.8 \pm 4$ & $4.3 \pm 0.3$ & $19.6 \pm 7$ & 2.8 & 10.9 \\
\hline Five & $2.7 \pm 0.6$ & $14.1 \pm 9$ & 3 & 13.9 & 2.8 & 12 & N/A & N/A \\
\hline
\end{tabular}

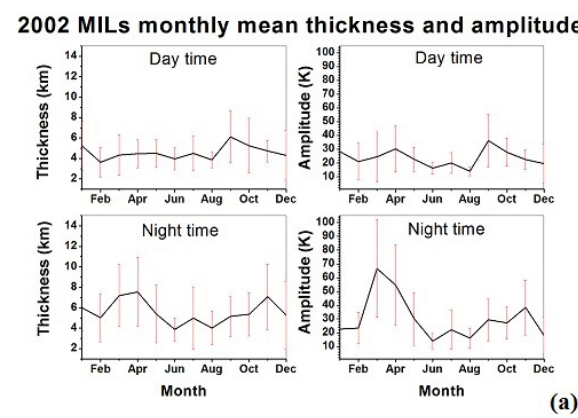

(a)

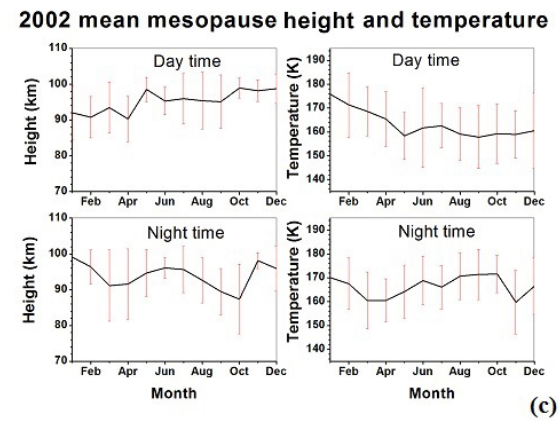

2008 MILs monthly mean thickness and amplitude

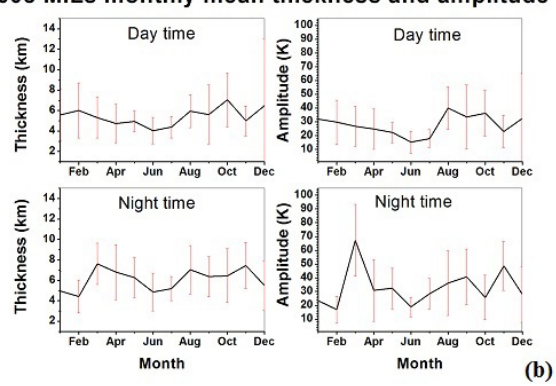

(b)
2008 mean mesopause height and temperature

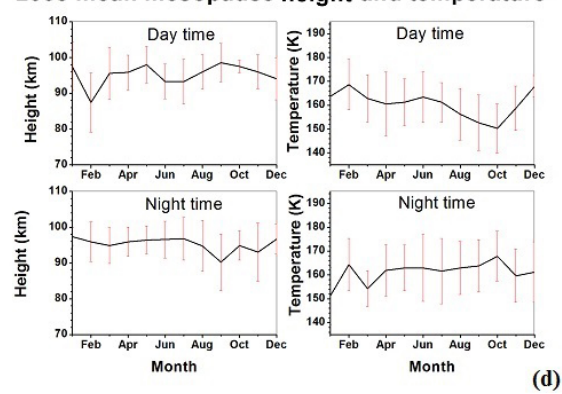

Figure 6. Seasonal variation of the monthly mean amplitude and thickness of MILs for the year 2002 (a) and 2008 (b). The bottom panels plot the variations of monthly mean mesopause height and temperature for 2002 (c) and 2008 (d). The error bars show the standard deviation in the monthly average values.

(Liu and Hagan, 1998). Also noteworthy is that the gravity wave dissipation also shows semi-annual variations (e.g. Taori et al., 2007). Further, the role of planetary waves and tides in the formation of lower MILs is well established (e.g. Meriwether and Gerrard, 2004), in which the critical level filtering generates the MILs. Therefore, it is logical to suggest that the occurrence of multiple MILs is a manifestation of a close coupling between chemistry and dynamics occurring at mesospheric altitudes. It is noteworthy that the seasonal variations are more pronounced in the night-time data compared the daytime data. The reason for such difference may be related to the variations of complex ozone and odd oxygen chemistry. During daytime, destruction of ozone by solar radiation dominates, while, in the night exothermic reaction between ozone and hydrogen may provide additional heating. However, we are unsure whether this is an outcome of chemical reaction or the dynamics, and this needs further debate.

Our investigation also suggests that on a few nights (Fig. 2b, d) the mesopause occurs at two distinct altitudes with one occurring at $\sim 75 \mathrm{~km}$ and another at $\sim 98 \mathrm{~km}$, which is in agreement with the results obtained by von Zhan (1996) that there are two preferential altitudes for the mesopause occurrences. It is also noted that for the majority of time, the mesopause altitude is near to $95-98 \mathrm{~km}$ during night and 98-100 km during daytime with a mean value of total data (including day-night data) of $\sim 98 \mathrm{~km}$ which is consistent with the recent reports that mesopause occurs around the 

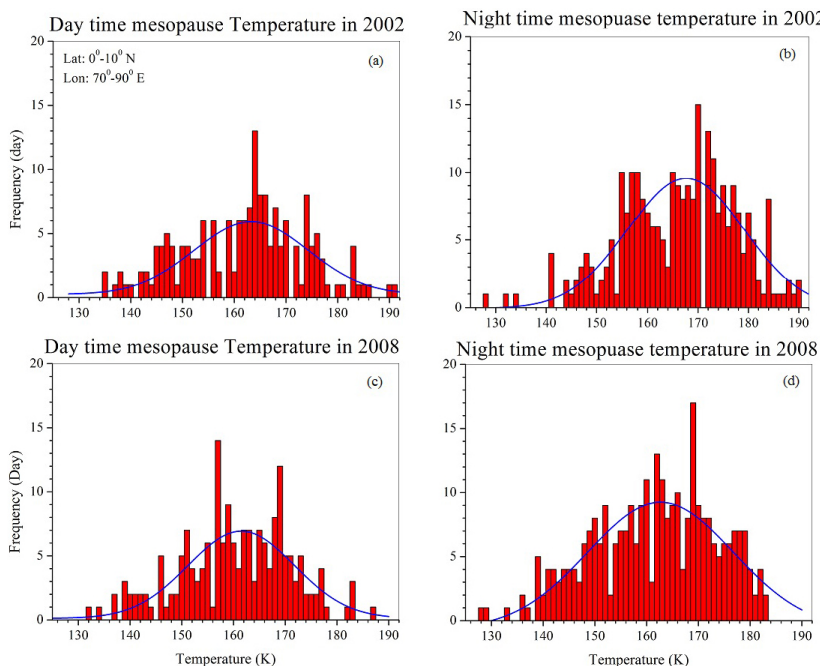

Figure 7. The mesopause temperature distribution for the year 2002/2008 (high/low solar activity) for daytime (a, c) and nighttime (b, d) measurements. Red bars show the mesopause temperature occurrences while the blue curves are the best fitted Gaussian curve.

$100 \mathrm{~km}$ altitudes (Ratnam et al., 2010). It is of importance that the mesopause temperature distributions are different in 2002 and 2008, with the distribution of the latter showing the temperature shifting to lower values. It is of interest, because recently Beig et al. (2008) have discussed the effects of solar activity on the mesopause structures and have suggested the solar contribution to be $\sim 1-2 \mathrm{~K}$ per 100 solar flux units. However, in recent times, there have also been reports of mesospheric cooling caused by the anthropogenic changes (e.g. Beig, 2011) suggesting a cooling rate ranging from -2 to $-4 \mathrm{~K}$ per decade. In this regard, our results showing the daytime temperatures during the high solar activity period (2002) to be warmer by $\sim 1.8 \mathrm{~K}$, and the night-time temperatures warmer by $\sim 5.1 \mathrm{~K}$ are interesting. Such a difference from day to night time can occur because of the combined effect of solar influence and the impact of large anthropogenic changes to the mesospheric heat budget. The changes in infrared cooling induced by the increasing $\mathrm{CO}_{2}$ and interplay of ozone chemistry may have profound effects on the middle atmospheric energetics and dynamics. Though we seem to have shown signatures of these processes in the data, investigations of competing roles of solar energy and anthropogenic changes on the mesospheric dynamics need to be explored further.

In a nutshell, the present results aim to put forward statistical aspects of multiple MILs and the variation of mesopause altitude and temperatures in front of the community seeking the attention of suitable observational and modelling efforts for a better understanding of various dynamical and chemical processes occurring in the Earth's atmosphere.

\section{Conclusions}

The present investigation based on the SABER data for the years 2002 and 2008 corresponding to high and low solar activity period reveals the following characteristics of middle atmospheric temperature structures.

1. The daytime MIL occurrences tend to show a large range with no specific peak in year 2002 while they seems to occur near to $71,82-86$ and $99 \mathrm{~km}$ altitudes during year 2008 .

2. During night-time, MIL occurrences have a lower peak in the $70-76 \mathrm{~km}$ altitude range, while the upper peak is situated at $95-98 \mathrm{~km}$ altitude range.

3. The MILs show peak occurrences near to the equinox months. The MIL thickness is found to be $4-6 \mathrm{~km}$ while the amplitudes vary from 10 to $60 \mathrm{~K}$.

4. The daytime mesopause altitude in 2002 and 2008 show the maximum occurrences around $99 \mathrm{~km}$ altitudes.

5. The night-time mesopause occurrences show two distinct peaks in 2002 with one at $\sim 75 \mathrm{~km}$ and another at $\sim 96-98 \mathrm{~km}$, while in 2008 only the peak occurring at $\sim 95-98 \mathrm{~km}$ is dominant.

6. The mesopause temperature distribution shows the daytime temperatures to be higher by $\sim 1.8 \mathrm{~K}$ in year 2002 compared to year 2008, while the night-time mesopause temperatures were found to be higher by $\sim 5.1 \mathrm{~K}$.

Acknowledgements. The data used in the present study are downloaded from http://saber.gats-inc.com/. The authors thank Mr. L. Basha for his help in downloading the SABER data. Ms. Disha Kapasi thanks the Indian Academy of Sciences, Indian National Science Academy and National Academy of Sciences for providing the summer research fellowship (2013) and the REAP programme of Jawaharlal Nehru Planetarium, Bangalore, under which part the work presented in this report was carried out

Topical Editor C. Jacobi thanks one anonymous referee for his/her help in evaluating this paper.

\section{References}

Batten, S., Fuller-Rowell, T. J., and Rees, D.: A Numerical Data Base for VAX and Personal Computers for Storage, Reconstruction, and Display of Global Thermospheric and Ionospheric Models, Planet. Space Sci., 35, 1167-1179, 1987.

Beig, G.: Long-term trends in the temperature of the mesosphere/lower thermosphere region: 1. Anthropogenic influences, J. Geophys. Res., 116, A00H11, doi:10.1029/2011JA016646, 2011.

Beig, G., Scheer, J., Mlynczak, M. G., and Keckhut, P.: Overview of the temperature response in the mesosphere and lower thermosphere to solar activity, Rev. Geophys., 46, RG3002, doi:10.1029/2007RG000236, 2008. 
Fadnavis, S. and Beig, G.: Mesospheric temperature inversions over the Indian tropical region, Ann. Geophys., 22, 3375-3382, doi:10.5194/angeo-22-3375-2004, 2004.

Fechine, J., Wrasse, C. M., Takahashi, H., Mlynczak, M. G., and Russell, J. M.: Lower-mesospheric inversion layers over Brazilian equatorial region using TIMED/SABER temperature profiles, Adv. Space Res., 41, 1447-1453, doi:10.1016/j.asr.2007.04.070, 2008.

Gan, Q., Zhang, S. D., and Yi, F.: TIMED/SABER observations of lower mesospheric inversion layers at low and middle latitudes, J. Geophys. Res., 117, D07109, doi:10.1029/2012JD017455, 2012.

Garcia-Comas, M., Lopez-Puertas, M., Marshall, B. T., Wintersteiner, P. P., Funke, B., Bermejo-Pantaleon, D., Mertens, C. J., Remsberg, E. E., Gordley, L. L., Mlynczak, M. G., and Russell III, J. M.: Errors in Sounding of the Atmosphere using Broadband Emission Radiometry (SABER) kinetic temperature caused by non-local-thermodynamic-equilibrium model parameters, J. Geophys. Res., 113, D24106, doi:10.1029/2008JD010105, 2008.

Hargreaves, J. K.: The solar-terrestrial environment, chapter-4, Cambridge University Press, ISBN 0-521-32748-2, 1992.

Leblanc, T. and Hauchecorne, A.: Recent observations of mesospheric temperature inversions, J. Geophys. Res., 102, 1947119482, doi:10.1029/97JD01445, 1997.

Liu, H. L. and Hagan, M. E.: Local heating/cooling of the mesosphere due to gravity wave and tidal coupling, Geophys. Res. Lett., 25, 941-944, 1998.

Meriwether, J. W. and Gardner, C.: A review of the mesosphere inversion layer phenomenon, J. Geophys. Res., 105, 405-416, 2000.

Meriwether, J. W. and Gerrard, A. J.: Mesospheric inversion layers and stratospheric temperature enhancements, Rev. Geophys., 42, RG3003, doi:10.1029/2003RG000133, 2004.

Meriwether, J. W. and Mlynczak, M. G.: Is chemical heating a major cause of the mesosphere inversion layer?, J. Geophys. Res., 100, 1379-1387, 1995.
Ratnam, M. V., Patra, A. K., and Krishna Murthy, B. V.: Tropical mesopause: Is it always close to $100 \mathrm{~km}$ ? J. Geophys. Res., 115, D06106, doi:10.1029/2009JD012531, 2010.

Russell III, J. M., Mlynczak, M. G., Gordley, L. L., Tansock, J., and Esplin, R.: An overview of the SABER experiment and preliminary calibration results, Proc. SPIE Int. Soc. Opt. Eng., 3756, 277-288, 1999.

Schmidlin, F. J.: Temperature inversions near 75 km, Geophys. Res. Lett., 3, 173-176, doi:10.1029/GL003i003p00173, 1976.

Siva Kumar, V., Bhavani Kumar, Y., Raghunath, K., Rao, P. B., Krishnaiah, M., Mizutani, K., Aoki, T., Yasui, M., and Itabe, T.: Lidar measurements of mesospheric temperature inversion at a low latitude, Ann. Geophys., 19, 1039-1044, doi:10.5194/angeo-191039-2001, 2001.

States, R. J. and Gardner, C. S.: Influence of the diurnal tide and thermospheric heat sources on the formation of mesospheric temperature inversion layers, Geophys. Res. Lett., 25, 1483-1491, 1998.

Szewczyk, A., Strelnikov, B., Rapp, M., Strelnikova, I., Baumgarten, G., Kaifler, N., Dunker, T., and Hoppe, U.-P.: Simultaneous observations of a Mesospheric Inversion Layer and turbulence during the ECOMA-2010 rocket campaign, Ann. Geophys., 31, 775-785, doi:10.5194/angeo-31-775-2013, 2013.

Taori, A., Guharay, A., and Taylor, M. J.: On the use of simultaneous measurements of $\mathrm{OH}$ and $\mathrm{O}_{2}$ emissions to investigate wave growth and dissipation, Ann. Geophys., 25, 639-643, doi:10.5194/angeo-25-639-2007, 2007.

von Zahn, U., Hoffner, J., Eska, V., and Alpers, M.: The mesopause altitude: Only two distinctive levels worldwide?, Geophys. Res. Lett., 23, 3231-3234, doi/10.1029/96GL03041, 1996. 